\title{
GALÁXIAS MURILIANAS
}

João Nilson P. Alencar (UFSC)

Recebido em 31 jul 2020. João Nilson P. Alencar é Professor da UFSC. Pós-doutor Aprovado em 02 set 2020.

pela UFMG (2013), doutor pela UFSC (1992) e mestre pela UEM (1984). Desde o mestrado, cuja pesquisa se ateve à obra de Murilo Rubião, tem produzido em sobre o tema, com publicação de artigos e capítulos de livro.

Resumo: Este ensaio procura ler a atualidade de Murilo Rubião em duplo movimento: por um lado, trabalhando com um suporte teórico contemporâneo, que dê conta das muitas entradas e saídas ao seu repertório. Por outro, o texto busca levantar o movimento de pesquisa e leitura do arquivo como espaço de descoberta e reinvenção - dois elementos fundamentais para não cair na armadilha da leitura canônica. Os dois movimentos são entrelaçados pela noção de uma política cultural no modernismo tardio, ao mesmo tempo em que lança a crítica como exploradora de universos, ou seja, criadora de ficções. Palavras-chave: Murilo Rubião; Arquivo; Literatura Brasileira; Modernismo Tardio; Educação.

Abstract: This essay intents to read the modernity of Murilo Rubião in a double movement: on the one hand, working with a contemporary theoretical support, which accounts for the many entries and exits to his repertoire. On the other hand, the text 
seeks to raise the movement of searching and reading the archive as a space for discovery and reinvention - two fundamental elements to avoid falling into the canonical reading trap. The two movements are intertwined by the notion of a cultural policy in late modernism, at the same time that it launches criticism as an explorer of universes, that is, creator of fictions. Keywords: Murilo Rubião; Archive; Brazilian literature; Late Modernism; Education.

\author{
Imperativo legal \\ para ser cumprida \\ operação-envolve \\ edifício - equivale \\ Portanto \\ Naturalmente \\ Consequência \\ Originário (153 \\ Preceito \\ Decorrência \\ Prescrição \\ Nasceu \\ Imposição \\ De ordem \\ legal ${ }^{1}$
}

Porque as suas ruinas têm sido agradáveis aos teus servos, e eles se compadecerão da sua terra. ${ }^{2}$

Por que ler Murilo Rubião hoje? Recorro, de imediato, ao que considero ser a porta "messiânica", como nos diz Benjamin, a passagem que nos faz transitar entre mundos e tempos: só

1 Manuscrito em tira de papel, com conta a caneta, seguido de anotações a lápis do texto "A diáspora". Pasta 06, Gaveta 01 In Acervo dos Escritores Mineiros - UFMG.

2 Epígrafe modificada para "A cidade mutilada". Murilo anota inicialmente "Como cantaremos o cântico do Senhor em terra estranha?" - Salmos, CXXXVI,4. "índices e epígrafes de A diáspora". Pasta 07 (Arquivo 2/Gaveta 1). Acervo dos Escritores Mineiros - UFMG. 
podemos ler Murilo hoje porque ele é a ruína moderna, uma vez que seus textos não cessam de se recompor. Exploremos.

Jacques Derrida defende a ideia, em seu Cartão Postal, de que a escrita é, antes de mais nada, uma carta, ilegível, endereçada ao futuro. Pois bem, este chegou. 100 anos após seu nascimento, celebramos hoje uma vida de proposições, cruzamentos, interpelações, rotas de fuga, e, não menos, espelhos com os quais permanentemente nos assombram imagens em que vamos nos reconhecendo e nos refazendo.

A escrita de Murilo Rubião nos inquieta e nos apaixona. Funciona como esta nave interestelar, uma Voyeger, lançada aos confins do universo, em que uma série de registros (visuais, verbais, auditivos) busca, incessantemente, uma vida que a leia. São sinais emitidos daqui, tentando provar que, em um ponto do universo, há vida. Quem eventualmente a encontrar terá que igualmente tentar 'decifrar' a 'origem' da sonda: desta feita, nunca dantes tantos signos foram tão prenhes de sentido. Por outro lado, quiçá mais importante do que revelar a origem, a nave-texto aponte a ideia de uma presença, completamente fantasmática, da questão da literatura. Este o primeiro, e talvez grande, enigma de por que ler Murilo Rubião.

Daniel Link, precisamente em seu livro Como se lê e outras intervenções críticas, no ensaio "Escada para o céu (Sobre ficção científica)", lembra que este gênero

é um relato do futuro posto no passado là diferença da utopia, que fala do futuro mas no presente, e da futurologia ou do discurso profético, que põem o futuro no futuro). Esta definição é 
precisa, econômica e reversível : tudo o que a ficção científica tematiza deve ser pensado em relação com alguma forma de futuro: as realidades alternativas, mesmo quando são postuladas a partir de (contra) um passado "historicamente verdadeiro", são remessas para um futuro, um futuro (do passado) alternativo. (2002, p.91-92)

Pois bem, este "relato do futuro no passado", ou, de forma "reversível", este passado que ainda não terminou de passar, como também nos adverte Deleuze, apresentaria, segundo Link, duas formas de ser lido: enquanto a utopia seria uma "variante sociopolítica da ficção científica", lendo-a ao contrário teríamos: que a "ficção científica [...] não seria senão a despolitização (a estetização, se se prefere) da utopia." (LINK, 2002, p.92), propondo, afinal, para esta ficção científica e na distância que separa a sua enunciação e seu enunciado (o passado), três categorias: a autonomização, estetização e despolitização, para, a seguir, traçar um paralelo exatamente com a literatura fantástica, relembrando similitudes entre esses gêneros, tais como a verossimilhança. No entanto, lembra o escritor da não menos enigmática e monstruosa La chancha con cadenas de 1994, que "[...] haveria uma garantia científica, externa ao gênero (e mesmo a toda a literatura), a partir da qual funcionam os mecanismos de verossimilização específicos da ficção científica" (LINK, 2002, p.93). Ao traçar as diferenças entre os dois gêneros (a ficção científica e a fantástica), Daniel Link comenta que ambos engendram a ideia da criação de "monstros", sendo a relação do fantástico vinculado a um campo simbólico: a Morte. Este, quiçá, seja um ponto em comum: ler Murilo hoje é encampar a discussão permanente de uma presença-ausência 
que ganha potência no universo do arquivo - e aqui as discussões feitas neste seminário dão conta do vasto campo existente - quer dizer - "por vir" - se lemos aqui a referência blanchotiana, por exemplo, quanto ao procedimento que engendra o mecanismo de leitura do texto - mecanismo que, segundo sabemos, Roland Barthes atribui um nascimento graças à clássica morte do autor. Esta história, voltando a Link, agora registrada na espectralidade de "La Chancha", é indicada também para o papel da crítica, definida na apresentação do livro como "um sistema regional de lucha y el crítico como um estratega en el combate literário" (LINK, 1994, p.7). Pensando assim, o campo literário se configuraria como espaço de tensão: campo de batalha onde as peças estão em permanente (des)alinhamento. O operador dessa maquinaria seria o crítico, também co-autor dos textos. Vejamos algumas outras peças.

A leitura é uma operação que, segundo Didi-Huberman, é anacrônica. E para Susan Buck-Morss, leva em consideração não o poder de origem definido como gênese material, no sentido cronológico pura e simplesmente. Antes, estaria igualmente para uma invenção. Somados os dois pontos de vistas, acrescidos da leitura benjaminiana da história, teríamos encenado o espaço virtual da leitura e seu semblante; da obra para o texto; do tempo recriado: ou seja, trata-se da própria ficção, aquilo que o próprio Rubião urdirá no belo enigma de "Marina, a intangível", quando da materialização de um processo de escritura de um texto: processo este que, passado diante de nossos olhos, será, antes de tudo, o jogo encenado da morte: uma presença (da escritura) ausente e vice-versa. Ora, sabemos que este texto, o de Marina, é engendrado 
por contos que o precederam, "Elvira e outros mistérios" e "Eunice e as flores amarelas", e todos nutridos da firme fonte machadiana.

Pouco ou nada apontada pela crítica, não nos esqueçamos que é no conto de Machado, não por acaso intitulado "Mariana", incluído em Várias Histórias, que há uma oscilação do quadro pendurado na parede, com o que Murilo aproveita a imagem e a desenvolve espe(ta)cularmente ao longo de sua vida literária, reaparecendo em Marina (notem a ergonomia do "nome" - e o processo de corte da letra, o "a", na constituição do mesmo). Murilo nos indica que a literatura é variação; corte; reinserção; invenção; modulação - a psicanálise falará de "flutuação". Exatamente esta incerteza cambiante foi um dos motivos que me levou a propor a leitura do acervo muriliano também como uma série de "tablaux" especialmente o estudo sobre a pasta intitulada por Murilo como "Anotações antigas para contos improváveis".

Por um lado, o título deste colóquio me remete, igualmente, a duas linhas teóricas: de um lado, o desconstrucionismo derridiano, com a linha instaurada ou instauradora do "mal de arquivo"4. Por outro, e nem sempre tão contrário, o processo de se refazer, da reescritura - de si, igualmente-, que um caminho freudiano poderia nos indicar, como, por exemplo, o belo ensaio: "Recordar, repetir, elaborar". Reunidos neste feixe, princípio elementar e primordial

3 In Arquivo - máquina de (des)montar. Ensaio apresentado como finalização do PósDoutorado desenvolvido no Pós-lit da UFMG. 2012-2013, sob orientação da Profa. Dra. Eneida Maria de Souza.

4 Elisabeth Roudinesco, em A análise e o arquivo, afirma que "Existe em todo historiador, em toda pessoa apaixonada pelo arquivo uma espécie de culto narcísico do arquivo, uma captação especular da narração histórica pelo arquivo, e é preciso se violentar para não ceder a ele.". (RJ - Zahar, 2006, p.9). Em seguida, aponta que "a obediência cega à positividade do arquivo, a seu poder absoluto, leva tanto a uma impossibilidade da história quanto a uma recusa do arquivo" (p.9). 
de toda antologia - lembremos o significado inicial desse vocábulo: feixe, reunião, florilégio -, os dois procedimentos de leitura nos encaminham para a questão que, crucial, pauta todo nosso debate neste encontro: afinal, que modernidade é a de Murilo Rubião?

Primeiramente, há que se lembrar, na vida do iniciante escritor da hoje Carmo de Minas, o impasse em que se encontrava: existe a questão paterna, que, como sabemos, representava um modelo de literatura que não acenava para o jovem escritor. Então, o primeiro grande desafio: como enfrentar o pai? Como inventar uma saída que não fosse desonrosa e, antes de mais nada, instigante, nova, afinal, moderna e, para aquele momento, modernista? A propósito, a correspondência com Mário de Andrade deixa claro este momento tenso e apaixonante. Como relembra o recente trabalho defendido pelo colega Cleber Cabral de Araújo, afixado em um dos pontos de sua tese, ele acrescenta exatamente uma das cartas "ausentes", a saber, uma resposta de Murilo a Mário que não se encontra na pequena, e importante, edição ${ }^{5}$ de Mário e o pirotécnico aprendiz. A missiva é de 2 de março de 1944, datilografada, e com acréscimos que demonstram que o contista mineiro fez rascunho, revisou e ficou, possivelmente, com uma cópia. Nesta, Murilo deflagra o momento angustiante de tatear um caminho novo:

Agora compreendo melhor a minha desorientação quanto ao meu caso pessoal. É essa "força devastadora de inteligência", que v. diz em uma das suas cartas, a me fazer oscilar entre negações

5 A edição de Mário e o pirotécnico aprendiz - Cartas de Mário de Andrade e Murilo Rubião traz a carta de Mário a Murilo, datada de SP, 27 de dezembro de 1943, pulando para a carta do mesmo Mário de 5 de abril de 1944. A edição é organizada por Marcos Antonio de Moraes. BH: UFMG; SP: IEB-USP; SP: Giordano, 1995, p.55-71. 
e afirmações. -Deus existe, não existe, devia existir, seria bom que existisse. Fico louco! E depois que embala, adeus! Todo apelo será inútil. A razão se descontrola e não sei mais de nada. Daí, talvez, os meus "desalentos quotidianos". Não? (CABRAL, 2016, p.323)

Portanto, poderíamos inferir, neste momento de busca, que a literatura, para Murilo, se constitui enquanto "espera". Escrever, reescrever, reelaborar... E nisso o arquivo é pródigo em atestar todo um universo que conspirava - e segue inspirando - a invenção de novas histórias e reescrita de tantas outras. Dessa forma, não seria impossível pleitear sua literatura como uma espécie de "work in progress". Ler Murilo seria o equivalente, na teoria benjaminiana, de um trabalho de escavação constante, em que a "ruína" e a "alegoria" são a pedra de toque e, nesse sentido, boa parte da fortuna crítica muriliana tem assim o demonstrado, bem como os estudos na linha da revisão pós-colonial, entre outras.

Ler o presente desta forma nos possibilita pensar igualmente uma teoria em que a "espera" e o "distanciamento" (freudiano, brechtiniano) se fazem presentes, como a que assistimos em O Brasil não é longe daqui - O narrador, a viagem, de 1990, em que a crítica Flora Sussekind evoca uma "demora", um "retard", como lembra Raul Antelo. A literatura muriliana ainda não chegou, apontando-nos o aparente paradoxo em que se encontra: vasto material \& a impossibilidade de dar conta de seus senderos; escrita materializada \& um evanescimento que retoma as categorias da modernidade como "fantasmática" e "fantasmal", ou ainda, "líquida", se se quisermos pensá-la com as modalidades de Bauman. Ainda assim, os textos murilianos nascem (e são 
quase forjados, uma vez que são fundamente marcados por "agon", o radical grego que indica a tensão, a luta) do impasse de um modernismo em franca cristalização, no entanto, ainda explorando os veios dos caminhos das pedras preciosas ainda não de todo encontradas. Para a crítica Flora Sussekind,

diferem os perfis, mas o diálogo persistente com o relato de viagem e o paisagismo [...] parece sugerir, entre outras coisas, que essas figuras de narrador necessitaram obrigatoriamente de um olhar-de-fora e de uma exibição - consciente ou não - de certa "sensação de não estar de todo" na sua composição. Necessidade que funciona como uma espécie de indicador prévio de deslocamento, distância, desenraizamento, marcas registradas [...] da escrita de ficção brasileira. (1990, p.20-21)

Destaquemos, pois, estes três elementos: "deslocamento", "distância" e "desenraizamento". Para o primeiro, Murilo estaria sintonizando-se com as forças emergentes das vanguardas europeias e latino-americanas: e aqui recordo o princípio borgeano da "atribuição errônea", com o que se traduziriam os outros dois elementos. Em relação à "distância", interligamo-la à própria força do "estranhamento", esta, sim, outra força motriz das histórias de Murilo. Um "estranhamento" - "familiar", uma "familiaridade" - estranha..., como nos lembra o "unheimlich" freudiano. Já o terceiro elemento, a do "desenraizamento", podemos lê-lo à luz do trabalho da própria Susan Buck-Morss (2002), em que defende a ideia de uma origem como invenção, criação, o que não estaria longe dos preceitos benjaminianos, como vimos. Afinal, também para Flora, há que se inventar um passado, e um presente, para a literatura. 
Se pensarmos "por que ler Murilo hoje", diria igualmente que sua literatura/vida é o que Alain Badiou definiu como "acontecimento". Vejamos:

As obras compõem uma verdade na dimensão pós-acontecimento, que institui a imposição de uma configuração artística. Uma verdade é, finalmente, uma configuração artística, iniciada por um acontecimento (um acontecimento é em geral um grupo de obras, um múltiplo singular de obras), e arriscadamente exposta sob a forma de obras que são seus pontos-sujeitos. / A unidade pertinente do pensamento da arte como verdade imanente e singular é, portanto, definitivamente, não a obra, nem o autor, mas a configuração artística iniciada por uma ruptura relativa ao acontecimento [...]. Essa configuração, que é um múltiplo genérico, não tem nome próprio, nem contorno finito, nem mesmo totalização possível sob um único predicado. Não é possível esgotála, apenas descrevê-la imperfeitamente. É uma verdade artística, e todos sabem que não existe verdade da verdade. (2002, p.24-25)

Esta necessidade de uma "imposição de uma configuração artística" assusta Murilo, ao mesmo tempo em que o lança a um processo sem volta. Sua literatura já está acontecendo... De outra forma, Murilo acaba por prefigurar o que Michel Foucault e outros críticos, como Giorgio Agamben, abordarão sobre o "dispositivo". Explorados os elementos "oikonômicos" e sua relação com a política, o crítico italiano não poupará argumento para rebater a tese de que a comunidade que vem é coisa do futuro. Os mecanismos de ligação, a saber, os processos de subjetivação, são mascarados por um controle que cria a ilusão dele mesmo, com o aparato moderno. 
Daí, o escritor toca numa questão, creio eu crucial, para pensar o contemporâneo: o conceito de "amigo", com o que também entrevemos, na figura de Murilo, o homem atravessado por interesses, por desejos, por prestatividade (amigável, profissional - pensemos no Murilo advogando e os inúmeros favores solicitados e prestados), um Murilo, como afirma a professora Eneida Maria de Souza, que se vê no cruzamento de janelas indiscretas (SOUZA, 2011).

Retomando Agamben, seus prefaciadores comentarão que "Num procedimento que mantém conexões com o pensamento barroco", o pensador italiano afirma que a entrada na temporalidade do presente é uma caminhada em direção a uma arqueologia daquilo que no presente não podemos viver e, "restando não vivido, é incessantemente relançado para a origem, sem jamais poder alcançá-la." (SCRAMIN; HONESKO, 2009, p.1718). Apresentando a relação do contemporâneo com a poesia, ainda frisarão que a "poesia, portanto, é sempre retorno, mas um retorno que é adiamento, retenção e não nostalgia ou busca por uma origem; é um caminhar, mas não é um simples marchar para frente, é um passo suspenso." (SCRAMIN; HONESKO, 2009, p.19). Agamben dirá que

o amigo não é um outro eu, mas uma alteridade imanente na "mesmidade", um tornar-se outro do mesmo. No ponto em que eu percebo minha existência como doce, a minha sensação é atravessada por um com-sentir que a desloca e deporta para o amigo, para o outro mesmo. A amizade é essa des-subjetivação no coração mesmo da sensação mais íntima de si (SCRAMIN; HONESKO, 2009, p.90) 
Rearmando os dados, pensemos que Murilo e sua obra, seu arquivo, funcionam como esta "alteridade imanente", onde toda uma geração se viu, se lançou, se atravessou, para encontrar um semblante moderno.

Nesse processo maquínico, no lance de armar e desarmar uma literatura, da qual Mallarmé foi mestre, ler Murilo Rubião hoje é, no jogo do desencontro do que é ser contemporâneo, formar um corpo, ainda que permanentemente transitório. Portanto, a armadilha da leitura de Murilo como cristalização apenas de uma geração indica um chão instável. Para tentar fugir dela, arma-se uma relação, em que figura a "intimidade", seja nos contos, ainda com a grande estratégia do absurdo encarado com naturalidade, seja no vasto material de iconografia, de manuscritos, de datiloscritos, bilhetes, folhas tão heterogêneas quanto primordiais na construção do mosaico arquivístico. Para Jean-Luc Nancy,

A intimidade não pode, com efeito, prescindir de estar ela mesma ordenada à coexistência geral. Mas a intimidade é também o elemento em que essa coexistência revela de maneira mais aguda um de seus traços fundamentais: a saber, que a coexistência e a simbolicidade não formam simplesmente a ordem de um continuum homogêneo. Na verdade, o comum, ou o que se poderia chamar de maneira menos confusa de com, nada possui de uma continuidade igual a si mesma. Ao contrário, continuidade aí se opera por descontinuidade. A relação que faz o sentido implica a diferença entre os sujeitos da relação sem a qual nenhuma relação seria possível. É o que na física elétrica se chama diferença de potencial ou ainda de tensão. (NANCY, 2015, p.15) 
Se tomarmos este campo da amizade, da intimidade, como espaço de uma descontinuidade tensionada, encontraremos inúmeras situações na obra muriliana, especialmente na sua epistolografia. Gostaria de me deter rapidamente em uma dessas situações a fim de pensarmos o momento atual brasileiro.

A ideia de intimidade, presente na discussão agambeniana, aponta também para o que poderíamos chamar de uma política cultural. Esta, fruto de cruzamentos de diversas fontes e encontros, é um pilar no modernismo brasileiro, se pensarmos que só a correspondência trocada entre os escritores novos e os considerados "mestres" ou "clássicos" serve como farol para entrarmos em túneis tão variados. Estamos nos anos 60. De Roma, escreve a Murilo um amigo seu, Antônio Barbero Braga Pinheiro, lotado no escritório do Brasil na capital italiana. $\mathrm{O}$ relato do amigo mostra os bastidores das intrigas inter-palacianas... intrigas que parecem esbarrar no pobre presente... como metáfora quase perfeita:

Escreve Antônio, em uma carta de 12 de janeiro de 1961:

Meu caro Murilo, a realidade é triste: O Escritório de Roma não é mais nada. Em 6 mêses êste moço asilhou[?] o que havia de melhor aqui. É uma morte lenta.../ [...] Embora não demonstre sou um homem só e procuro, no trabalho, preencher e superar esta lacuna do meu íntimo. Parte de mim, da minha juventude, do meu trabalho, da minha capacidade está aqui neste Escritório. [...]/ Murilo, não cante carta e escreva-me, sempre que houver tempo disponível, pois carta é uma notícia e notícia é sempre uma presença./ Com um grande abraço, seu amigo certo, / Antônio. ${ }^{6}$

6 Carta no Arquivo do Escritores Mineiros - (Arq. 1/Gav. 6/Pasta 01) - Série Correspondência com amigos/ Subsérie Correspondência com Amigos (1935-1966) - Exterior. 
Pouco tempo antes, o próprio Antônio havia confidenciado a Murilo uma série de questões problemáticas, reveladoras da situação pós-eleição (governamental) no Brasil e o consequente quadro em Roma. Como se sabe, Murilo havia recém passado na Espanha como adido cultural brasileiro. A data é de 21 de abril de 1960. O amigo confessa:

Sua carta chegou no momento exato, pois, há mais de uma semana que ando num "spleen" bastante desagradável. E, não é para menos, tendo em vista o ponto a que chegou este Escritório, com o péssimo comportamento e intrigas de certos elementos locais.

O Barreto, como você não ignora, se encontra no Rio criando mil e umas confusões para justificar a sua permanência no Brasil. Tenho sido sabotado em meu trabalho em toda a linha. Imagine só que, para não aparecer a ausencia [sic] do Barreto, inventaram uma ordem de serviço de que eu não mais deveria assinar "Chefe Substituto" e sim "Responsável pelo Expediente".

Você já foi meu chefe e sabe que sou desprovido de qualquer vaidade, mas que sou muito cioso do meu valor e capacidade funcional. Já me sinto muito velho para ser desmoralizado. Você conhece muito bem a situação do Escritório de Roma e de certos elementos contratados que aqui circulam. Pois bem, tais elementos resolveram tirar a mascara e colocar as garras de fora, tentando um ato de desmoralização e amotinamento no Escritório, ao pensarem que com a perda de meu título de Chefe Substituto, consequentemente, havia perdido, também, a autoridade. Enganaram-se e muito!! 
O relato continua, com a chegada de duas funcionárias contratadas e de "péssima reputação funcional e moral" (Maria Helena Falcão e Nadima Chaoul [ex-funcionária da Panair]). Vêm questões como falta de pagamento, comportamento "torpe" e atitude "maldosa"; escritas críticas ao Chefe do Departamento, à filha do Ministro (Ana Maria Nóbrega), Deputados e autoridades, comentando que as duas funcionárias estavam passando fome etc... Daí, o pedido:

Gostaria que você contasse ao Presidente como está este escritório e os maus elementos locais que aqui existem, pois sei que a inveja, a intriga e a má fé que andam aí, contra mim, é muito grande. 0 interessante seria que o Presidente mandasse chamar o Barreto e desse ordem para dispensálas, pois apesar dele fazer a pior ausência delas por outro lado faz também o jogo duplo. (fl.3)

E completa:

Meu caro Murilo, isto aqui virou "Torre de Babel". Ninguém mais se entende. A maledicência e a intriga são senhoras, absolutas, da situação e já não se sabe mais em quem acreditar. $O$ desrespeito é de tal ordem ordem[sic] que o Escritório tomou ares de "bar", a ponto de tomarem cerveja e aperitivos durante o expediente, solicitando o serviço do bar que temos perto do Escritório. E tudo isto é feito ostensivamente, pois, alegam que o Chefe de direito de fato é o Barreto, que está no Rio, que é quem Ihes dá todo o apoio e que eu sou um simples responsável pelo expediente.

E segue, contando outra situação-bomba, com um dos funcionários do Ministério do Trabalho quando Murilo esteve por lá. Trata-se de uma longuíssima carta, com umas sete páginas, 
toda datilografada! Encerra-a com as devidas desculpas, e com a afirmação de que "Apavoro-me vendo o barco afundar-se lentamente nesse mar de luxúria, imundície e vergonha, e eu tendo de cruzar os braços sem [rasura] forças para salvá-lo" (p.7).

O extenso relato, e aqui o faço resumindo, com recorte bem preciso das cartas trocadas, põe em evidência não só a alta estima que muitos nutriam por Murilo e por sua "diplomacia", sempre cordata e conciliatória - vertente que Murilo nutre desde as primeiras experiências no campo do Direito... -, reforçadas pelos caminhos trilhados entre a vida cultural, e literária propriamente dita, como a vinculada à atividade pública e administrativa. De golpe, o que nos choca é a atualidade do relato. As "coincidências" entre um esquema de funcionamento das relações públicas e privadas no e do Brasil são aterrorizantes, se pensarmos que entre a década de 60 até agora lá se vai mais de meio século...

Este trabalho de arqueologia revela nossas fraturas expostas. Essa relação de vida íntima, pública e a produção literária parecem conter, na leitura da trama, um componente inusitado: o dado histórico, portanto, lido posteriormente, revela que seus sentidos armam-se de distintas formas. O parentesco com os dias atuais é tão assustador e "fantástico" quanto os próprios contos murilianos. Para Agamben, se lermos a história da modernidade como história cindida, como vimos em Homo Sacer, e a relação de pertencimento excludente, encontraremos neste arquivo indícios desse movimento. Para o crítico italiano, a regra e a exceção encontram seu componente na ideia, retomada de uma conferência de Derrida (1989), e da tradição romana e, nos tempos modernos, da época da Revolução Francesa, da 
intangibilidade da lei, inclusive em relação ao soberano, que não pode anulá-la nem modificála. Nesse sentido, a doutrina moderna distingue a eficácia da lei, que decorre de modo absoluto de todo ato legislativo válido e consiste na produção de efeitos jurídicos, e força de lei que, ao contrário, é um conceito relativo que expressa a posição da lei ou dos atos a ela assimilados em relação aos outros atos do ordenamento jurídico, dotados de força superior à lei (como é o caso da constituição) ou de força inferior a ela (os decretos e regulamentos promulgados pelo executivo) (QUADRI, 1979, p.10 Apud AGAMBEN, 2004, p.60.)

Nada nos surpreenderia encontrar, diante do tempo, do tempo do Ex-Mágico, uma literatura que procede de maneira semelhante: parece querer enfrentar os dois: a "eficácia" da lei é posta em cheque, tanto quanto por "força de lei" todos os comportamentos subjugados e denunciados na literatura de Murilo. O que parece ser a exceção, ou seja, os milhares de documentos em seu arquivo que ficaram no "submundo" (e aqui valeria uma leitura atenta da série de textos que Murilo ensaia, por exemplo, sobre o "esgoto"... e a vida que tenta nascer dali, presente em seus inéditos manuscritos), escondidos da luz das publicações oficiais, encontram no impasse gerado pela doação deliberada a uma instituição que os conserve, guarde, estude... (os arcontes derridianos, por excelência), uma saída para o que não "deveria" ter vindo à tona.

Afinal, o que há neste arquivo, nesta literatura, que tanto nos atrai? Como operar a máquina de (des)montar? Se a questão, passada a discussão primeira da pós-modernidade, que pleiteava, como em Frederic Jameson, um conceito de "renarrativização dos 
fragmentos", onde o desafio das peças do jogo estaria em como colar os cacos pós explosão do sentido do texto único, o câmbio da problemática da leitura não residiria mais em o que ler, mas em "como se ler" o material disponível. Portanto, o que ganha dimensão é o procedimento - lembremos do famoso ensaio de Victor Chklovski, "A Arte como Procedimento", de 1976. O século XXI nos exige, mais do que o campo cheio (o sentido pleno), o esvaziamento deste. E este método de leitura, se assim podemos chamá-lo, leva em conta o que também Murilo nos legou: seus textos nos deram não só um futuro, mas vários horizontes. Na máquina de leitura, erotizada como queria Barthes, nave intergalática que emite e recebe sinais, portanto, na flutuação plena de sentidos, a literatura muriliana não é apenas uma denotação, mas uma "detonação", como afirmará, no limiar das conexões, Gregory Ulmer (1985) em sua "Post(e)-pedagogy". Este o grande legado de Murilo: fazer sonhar, inventar, um mundo que ainda não chegou. ${ }^{7}$

\section{REFERÊNCIAS}

AGAMBEN, Giorgio (2004). Estado de exceção. Iraci D. Poleti (Trad.). São Paulo: Boitempo.

BADIOU, Alain (2002). Pequeno manual de inestética. Marina Appenzeller (Trad.). São Paulo: Estação Liberdade.

BUCK-MORSS, Susan (2002). Dialética do olhar: Walter Benjamin e o projeto das Passagens. Ana Luiza de Andrade (Trad.). Belo Horizonte: UFMG; Chapecó: Universitária Argos.

7 Também Roberto Bressane, em recente declaração, afirmou que precisamos de mais fantasia e mais invenção, advogando que a "presença do fantástico levaria a nossa prosa contemporânea a caminhos menos óbvios e mais intrigantes. [...] Atuar como um filtro ao ruído do mundo" In http://etudeslusophonesparis4.blogspot.com.br/2016/11/atuarcomo-um-filtro-ao-ruido-do-mundo.html Acesso em: 12.Nov.2016. 
CABRAL, Cleber Araújo (2016). Aos leitores, as cartas: proposta de edição anotada da correspondência de Murilo Rubião com Fernando Sabino, Mário de Andrade e Otto Lara Resende. 361f. Tese (Doutorado em Teoria da Literatura e Literatura Comparada) - Programa de Pós-Graduação em Estudos Literários, Universidade Federal de Minas Gerais, Belo Horizonte.

CHKLOVSKI, Victor (1976). “A arte como procedimento”. In: TOLEDO, Dionísio de Oliveira (Org.). Teoria da literatura - formalistas russos. 4.ed. Porto Alegre: Globo, p.39-56.

LINK, Daniel (1994). La chancha con cadenas. Doce ensayos de literatura argentina. Buenos Aires: Ediciones del eclipse.

(2002). Como se lê e outras intervenções críticas. Jorge Wolff (Trad.).

Argos: Chapecó.

NANCY, Jean-Luc (2015). Corpo, fora. Márcia Sá Cavalcanti Schuback (Trad.). Rio de Janeiro: 7Letras.

SCRAMIN, Susana; HONESKO, Vinícius Nicastro (2009). "Apresentação". In: AGAMBEN, G. O que é o contemporâneo. Vinícius Nicastro Honeski (Trad.). Chapecó: Argos, p.17-18.

SOUZA, Eneida Maria de (2011). Janelas Indiscretas: ensaios de crítica biográfica. Belo Horizonte: Ed.UFMG.

SUSSEKIND, Flora (1990). O Brasil não é longe daqui - O narrador, a viagem. São Paulo: Cia. das Letras.

ULMER, Gregory L. (1985). Applied Grammatology: Post(e)-Pedagogy from Jacques Derrida to Joseph Beuys. Baltimore and London: Johns Hopkins Press Ltd. 